\title{
Los horizontes de la medicina de urgencias
}

\author{
Luis Antonio Gorordo-Delsol* \\ Editor Asociado, Revista de Educación e Investigación en Emergencias, Unidad de Cuidados Intensivos Adultos, Hospital Juárez de México, Ciudad \\ de México, México
}

La Medicina de Urgencias (MU) tiene una historia tan antigua como la misma medicina, los pacientes con dolencias agudas acudían con prontitud a recibir atención sanitaria de quien los pudiera atender. Con la creación de sanatorios y hospitales se notó la necesidad de tener personal capacitado en la atención inmediata, con destreza clínica y gran capacidad resolutiva ${ }^{1,2}$. A lo largo del tiempo, los programas de especialización en MU han expandido su campo de acción hacia otros horizontes ${ }^{3}$, lo que permitió a los urgenciólogos ocupar otros espacios.

Un ejemplo claro es la Medicina Crítica, que en sus inicios fue dominada por cirujanos, luego por anestesiólogos y a finales del siglo pasado por internistas; hoy en día es muy común encontrar a urgenciólogos en el posgrado o trabajando en las Unidades de Cuidados Intensivos ${ }^{3}$. Conforme creció la necesidad de capacitar mejor a los estudiantes de medicina y enfermería en la MU, se tuvieron que crear métodos didácticos adecuados a esta especialidad, que incluyeron profundos cambios en los programas académicos de pregrado y posgrado 4 , por lo que hoy contamos con diversas especialidades de entrada indirecta (léase subespecialidades) con MU como prerrequisito: Medicina Crítica, Reanimación, Toxicología, Cuidados Paliativos, Atención a quemados y Urgencias Neurológicas, sin dejar de lado otros cursos aplicados a la MU, como la docencia, administración, gestión de la calidad, etc.

La Medicina Espacial no está exenta de nuestra invasión, y con mucha razón, pues la mayoría de los problemas que se puedan presentar durante las misiones espaciales tendrán carácter de emergencia médica 0 quirúrgica, donde los urgenciólogos podemos impactar positivamente. Algunos protocolos como Basic Life Support (BLS), Advance Cardiac Life Support (ACLS) y Advance Trauma Life Support (ATLS) pueden ser aplicados (con adaptación y entrenamiento riguroso en ambientes de microgravedad) por los astronautas ${ }^{5}$, y no sorprende que poco a poco los especialistas en Urgencias incursionemos en estas simulaciones, entrenamientos, protocolos de atención e investigación, como lo podemos ver en un interesante manuscrito de este número ${ }^{6}$. El eje transversal en el que se practica la MU nos permite impactar en distintos campos de acción y con una profundidad variable, la participación de especialistas de Urgencias en múltiples subespecialidades, áreas y ahora en la Medicina Espacial demuestra que hemos superado los horizontes de nuestra especialidad ¿hasta dónde llegará la Medicina de Urgencias?

\section{Bibliografía}

1. Castillo-de Los Santos R. Medicina de urgencias: una especialidad nueva para el gremio médico militar, pero vital para el servicio de sanidad militar. Rev Sanid Milit Mex. 2017:71:290-9.

2. Alagappan K, Holliman CJ. History of the development of international emergency medicine. Emerg Med Clin North Am. 2005;23(1):1-10.

3. Gorordo-Delsol LA. El papel del urgenciólogo como intensivista. En: Loria-Castellanos J. Medicina de Urgencias en México: tres décadas, logros y retos. 1. ${ }^{a}$ ed. México: Ediciones Berit FGV SA de CV; 2017. pp. 91-95.

4. Ramos-Rincón JM, Pérez-Esteban C, Sigüenza-Ortiz J, García-Barbero M Caturla-Such J. Docencia en grado y posgrado en Medicina de Urgencias y Emergencias en las facultades de medicina españolas. Educación Médica. 2018. doi.org/10.1016/j.edumed.2018.04.022

5. Sánchez-Zúñiga MJ, Medveczky-Ordóñez NI. Urgencias médicas en vuelos espaciales. En: Carrillo-Esper R, Díaz Ponce-Medrano JA, Padrón-San Juan L. Medicina Espacial. 1. ${ }^{\text {a }}$ ed. México: Intersistemas; 2016. pp. 291-298.

6. Labastida-Mercado N. Experiencia Mexicana de la Medicina de Urgencias en las Misiones Análogas a Marte. Rev Educ Investig Emer; 2019;1(2): 38-41.

\section{Correspondencia:}

*Luis Antonio Gorordo-Delsol

Av. Instituto Politécnico Nacional, 5160

Col. Magdalena de las Salinas, Del. Gustavo A. Madero Fecha de recepción: 11-02-2019

C.P. 07760, Ciudad de México, México

E-mail: luis.gorordodelsol@icloud.com
Disponible en internet: 20-06-2019

Rev Educ Investig Emer. 2019;1(2):37-37 www.medicinadeemergencias.com

2604-6520 C 2019 Sociedad Mexicana de Medicina de Emergencias, AC. Publicado por Permanyer México SA de CV. Este es un artículo Open Access bajo la licencia CC BY-NC-ND (http://creativecommons.org/licenses/by-nc-nd/4.0/). 